\title{
Socio-ecological challenges to Indian Pangolin in Pakistan: A review
}

\author{
Muhammad Umar, Aleena Naeem and Mubashar Hussain* \\ Department of Zoology, University of Gujrat, Punjab-Pakistan \\ *Corresponding author's email: dr.mubashar@uog.edu.pk \\ Citation \\ Muhammad Umar, Aleena Naeem and Mubashar Hussain. Socio-ecological challenges to Indian Pangolin in \\ Pakistan: A review. Pure and Applied Biology. Vol. 9, Issue 4, pp2207-2013.
}

http://dx.doi.org/10.19045/bspab.2020.90236

\begin{tabular}{llll}
\hline \hline Received: 01/02/2020 & Revised: 25/05/2020 & Accepted: 21/06/2020 & Online First: 07/07/2020 \\
\hline \hline
\end{tabular}

\section{Abstract}

Indian Pangolin (Manis crassicaudata) also called as thick-tailed pangolin and scaly anteater, native to the Indian subcontinent is an endangered mammalian species (Manidae; Mammalia). The pangolin inhabits areas with prey i.e. a termite (Odontotermes obesus) and two black ants (Camponotus confucii and Camponotus compressus). We reviewed the published research work carried on Indian pangolin to identify the reasons for the decline in its population in Pakistan. We identified that only a few studies have been conducted on the biology, diversity, ecology, and potential threats to M. crassicaudata in Pakistan. However, some data is available on websites of organizations working on the conservation of animals, personal communications, newspaper articles and reports. Its populations have been reported from forests, grasslands, sub-mountainous landscapes, and degraded habitats. Pangolins are under serious threat in Pakistan due to their massive killing for illegal wildlife trade, medicinal and cultural values. Pangolin population is facing declining trend in its population in Northern Punjab and Azad Kashmir (personal communications) due to habitat degradation and deforestation and hunting for fun. Conservation of Indian pangolin needs social awareness through electronic and print media. It is suggested that the curriculum of science at primary and secondary levels should contain introduction of Critically Endangered (CR), Endangered (EN) and Vulnerable (VU) species like Indian Pangolin (Endangered). We suggest to explore the population dynamics of Indian Pangolin in relation to distribution patterns, feeding preferences, prey availability, habitat suitability and threats.

Keywords: Ants, Feeding Preference, Habitat Suitability, Pangolin, Termites

\section{Introduction}

Indian Pangolin (Mammalia; Pholidota) also called as scaly ant eater having a unique rigid keratinized protective 11-13 rows on body of blonde-striated scales [1]. Asia and Africa inhabit eight extant species of pangolins [2]. In Pakistan, Pangolin is known as "Salla" [3]. It has significance in the natural biological control of termites and ants. Their burrows provide breeding habitat and shelter for other species [4]. In the IUCN Red List of Threatened Species, it is included in
"Endangered Species" mainly due to hunting and increased poaching [5]. About $50 \%$ decline in the population of pangolin has been estimated in its range in the next 21 years [6]. As an important wild mammal, it has great importance in the biodiversity of Pakistan, especially since it has been declared as an endangered species.

\section{Conservation status}

Currently, M. crassicaudata is an endangered species in its distribution range viz. Bangladesh, India Pakistan, Nepal and Sri 
Lanka [7, 8]. Since 1975, M. crassicaudata has been categorized under Appendix II of the CITES (the Convention on International Trade in Endangered Species of Wild Fauna and Flora) [9]. In 2000, zero export quotas have been assigned to pangolin in the international trade [10].

Indian pangolin is basically solitary, shy, nocturnal, fossorial \& small sized mammal whose upper part of body with tail is covered with overlapping horny and yellowish-brown scales [11]. Pangolins have a mean gestation period of 67 days. It weighs about $0.35 \mathrm{~kg}$ at birth, adult grows to a weight $13.015 \mathrm{~kg}$. Body length of pangolin reaches $2.0-2.2 \mathrm{ft}$ including 1.5-1.8 ft armored. Scales ranges from brownish to yellowish with skin appearing brownish. It makes two types of burrows i.e. feeding \& living. Feeding burrows are smaller, formed in spring in the presence of plenty of prey while living burrows are wider, deeper \& owned for a longer time. The average height of feeding burrow recorded was $19.73 \pm 2.78 \mathrm{~cm}$ while its average width and depth were found 19.46 $\pm 2.86 \mathrm{~cm}$ and $0.37 \pm 0.02 \mathrm{~m}$, respectively. While the average width of living burrow opening was $24.70 \pm 0.99 \mathrm{~cm}$, while the average burrow depth recorded was $2.95 \pm$ $0.10 \mathrm{~m}$ [12].

Pangolin feed on termite and ant populations gregariously i.e. 70 million insects are consumed by a single pangolin $[8,13]$. Pangolins mark their territory by urinating and emitting musky anal secretion. Its explorative behavior is defined by three ways i.e. sniffing, bipedal stand \& secretions while defense behavior includes defensive positions \& vocalization [14]. Chain-link mesh, smelling, looking at each other, and squirting urine are important mating patterns [15].

In Pakistan, Indian pangolin needs to be conserved in situ while ex situ conservation efforts should be made to reverse the declining trend of the population growth.

\section{Distribution}

Fossil Pholidotes have also been found in Asia, Africa, Europe and North America [16] and is distributed both in plain and hilly areas [17]. Indian Pangolin has distribution in South Asia [6, 18] and among all extant species of pangolin in the order Pholidota, only one member $M$. crassicaudata is reported from Pakistan; and also found in Bangladesh, India, Sri Lanka and Western China [19, 20]. The distribution patterns, population estimates and socio-ecological threats to the Indian Pangolin have not been studied extensively especially in Pakistan. However, diversity and distribution of Indian pangolin have been explored from Azad Kashmir and Pothwar region [8, 12, 21, 22]. The studies have recorded its populations in Sialkot, Jhelum, Gujrat and Attock and Kohat, Mardan, Peshawar, Kotli, Mirpur and Bhimber in Azad Jammu and Kashmir. In Sindh, it has been reported from Dadu and Larkana whereas in Baluchistan the occurrence from Makran and Lasbela regions has been reported $[9,23]$. A fossil ancestor of M. crassicaudata has been discovered from Dadu near Manchar Lake [24]. Indian Pangolin has been reported from Margalla Hills National Park (elevations 462-1,046 m) and Pir Lasura National Park (elevation 699$1559 \mathrm{~m}$ ) which is the highest reported range in Pakistan [20, 23, 25]. However, its occurrence may have not been reported or explored from many potential areas including Bahawalpur division. It has been documented from different parts of country, however, many potential areas with similar habitat characters and availability of prey abundance (ants and termites) need to be explored.

\section{Threats to Indian Pangolin}

The literature indicated scanty work on the diversity, population dynamics, distribution and potential threats to the Indian Pangolin in Pakistan. We have explored, in this review, population dynamics and distribution and potential threats in socio-ecological context 
from the published literature in articles, book chapters, newspaper stories and personal communications. We have identified from published literature that decline in the population of Indian pangolin has been attributed to the socio-economic issues rather than socio-ecological. However, the impact of ecological changes in its areas from where it has been reported cannot be overlooked. We did not find any published evidence highlighting the impact of habitat modification, agricultural practices (use of pesticides to manage termites and ants) and climate change on the biology and ecology of Pangolin. Perusal literature showed more focus has been given on illegal hunting and trafficking of its parts. Some important issues have been provided below.

\section{Hunting}

Indian Pangolin has been found under threats including massive hunting pressure mainly for its scales, medicinal importance, and magical powers [26]. Similarly, killing of Indian Pangolin has been reported from Sumatra, Indonesia [27] and peninsular Malaysia [28]. Studies reported 30,000 pangolin killings from 2000 to 2007 in the Southeast Asia [28]. Indian Pangolin is highly desirable species for hunting due to its flesh, skin and scales [29] that has served as a major cause of being declared as an "endangered species" [30]. Despite legal protection for hunting or selling of pangolins for any purpose under the Wildlife (Protection) Act 1972 and inclusion in Appendix II of CITES, the Convention on International Trade in Endangered Species of Wild Fauna and Flora in 2000 [9], the hunting of pangolin has remained consistent in its whole range of habitat. It has been reported for illegal hunting and being exported for medicines and many other reasons [5]. The current estimates of population indicate that the species would soon cease to exist if not conserved $[8,16]$. The declining trend of population in Pakistan has been attributed to its killing mainly for the scales to be used in bullet proof jackets and making traditional medicines $[8,12,31,32]$. This species is hunted by the local peoples for its flesh, skin and scales [33]. Due to massive hunting in wild habitat, Indian Pangolin is least studied species in country and faces high risk of extinction [30]. Its population is expected to keep on declining at extreme limit and the vital species may be lost very soon without conservation efforts. Similarly, another study conducted in the Potohar Plateau (Punjab, Pakistan) showed that density estimates were higher in 2010 as compared to 2012. This decrease in density estimate occurred due to killing of species in the region for illegal trade of scales $[8,34]$.

Local hunting for the trade of scales, use in medicine and killing based on socio-cultural context (human conflict) and hunting for the fun are major reasons for the decline in the population of Indian pangolin.

\section{Local and international trading}

Historically, Pangolin has been trading internationally because of their commercial importance [34]. The species is killed mainly for its scales which have importance of local and international trade value [8, 32, 33]. However in China by the mid- 1990s, the population become commercially extinct and became dependent on imports mainly from Southeast Asia [30, 35] and this has transformed local trade into international trade.

\section{For scales}

A survey was conducted to identify the major causes of its hunting that provided that the major reason was scales [21, 22, 36], medicinal importance [29] and ornamental uses [17]. It has been reported that sometime live animal is sold @ Rs.10, 000 to 15,000 per animal [21]. Illegal trade and export of scales to China \& Vietnam for medicinal purpose has been reported in personal communication. The literature indicated that during 2000-2013, millions of individuals 
were killed for trade and export of scales [33]. Indian Pangolin hunting rate is highest in India i.e. Arunachal Pradesh \& Odisha [37]. Trading of Pangolin has been found internationally due to their commercial importance [34]. The species is killed mainly for its scales which have importance of local and international trade value [8]. This has driven local trade dynamics with international trade being substituted for regional use in most of the areas. The major reason behind local trade of Indian Pangolin is for scales \& meat. It is reported that various areas of India i.e. Andhra Pradesh, Kerala, Odisha, Manipur \& Pakistan i.e. Peshawar, Lasbella \& Makran are involved in its illegal trade [38]. Different methods are used for their capturing i.e. caught when sighted or by digging of their burrows. They are killed by placing them in boiling water while the scales are removed by skinning or peeling off [39]. Scales has been found one of the main reasons for the killing of pangolins Pakistan.

\section{Used as food and in medicines}

The pangolin flesh and fat has been used in medicines [40]. Traditionally, it is found that scaly anteater has crucial value in Chinese medical \& food industry. Due to their excessive use, they became extinct in China since 1990 so that China has to export them from Asian countries under illegal trade [30]. A study has reported that Pangolin parts are using in medicines in South Korea, East Asia. Chinese and other traditional medicines also use the scales of the species to make traditional medicines known as "muti" [41]. They are used as protein source in Veitnam \& China [30]. Ethno-medical practitioners (hakims) believe Indian Pangolin as a valuable source of traditional medicines [24].

\section{Habitat degradation}

Habitat degradation is another important factor for its population decline $[8,21]$. Though its prey species i.e. ants $\&$ termites are abundant. Increased deforestation and increase in the agricultural landscapes characterized by use farm inputs (fertilizers, pesticides, farm machinery, etc.) posing serious threats to pangolins. As they are burrowing animals \& make two types of burrows i.e. living \& food burrows, so the pesticides used for agriculture affects their habitat $[8,12]$.

\section{Slow reproduction rate}

Breeding season (July to October) with one generation per year with a litter size of one to two in Potohar region [23]. One of the major drawbacks for declining of population of Indian Pangolin is its very slow reproduction rate and poor breeding results in captivity $[42,43]$. In Pakistan, little efforts have been made on its captive breeding.

\section{Coincidental killing}

Though coincidental killing has been on the record and also been communicated. Coincidental killing of the species by farmers and local hunters has not been identified as major cause for the declining trend in the population of Indian pangolin. It has been reported that coincidental killing is less likely to cause a serious decline in the abundance [8].

\section{Conclusion}

Indian pangolin remains as one of the least studied and highest trafficked mammal from Pakistan. During the $1^{\text {st }}$ two decades of the $21^{\text {st }}$ century, the declining trend in its population has been attributed to increased habitat loss, hunting due to its demand for its meat, scales, and derived products in addition to socio-cultural beliefs.

The dearth of scientific research on $M$. crassicaudata is the major concern in conservation planning of the species in Pakistan. This review identifies three research areas to be prioritized in order to generate the essential information to assess the needs for in-situ conservation planning of M. crassicaudata i.e. (1) Ecology, behavior and population abundance of species; (2) Assessment of hunting, poaching, and trafficking levels of the species; and (3) 
evaluation of threats due to habitat modification and degradation. Changes in the community perceptions and beliefs about Indian pangolin and public awareness is mandatory for its conservation.

\section{Authors' contributions}

Conceived idea: M Umar \& M Hussain, Performed literature review: M Umar \& M Hussain, Organized data: A Naeem, M Umar $\&$ M Hussain, Wrote the paper: M Hussain \& M Umar.

\section{References}

1. Atkins WA (2004). Pholidota pangolins (Manidae). In B. Grzimek, D. G. Kleiman, V. Geist, and M. C. McDade (eds.), Grzimek's Animal Life Encyclopedia, volume 16. Detroit: Thomson-Gale.

2. Lekagul B \& McNeely JA (1977). Mammals of Thailand. Association for the Conservation of Wildlife, Sahakarnbhat, Co, Bangkok, pp758.

3. Prater SH (1971). The book of Indian animals. $3^{\text {rd }}$ (revised) Ed. Bombay Natural History Society (Mumbai), pp 324.

4. Hansell MH (1993). The ecological impact of animal nests and burrows. Funct Ecol 7(1): 5-12.

5. Baillie J, Challender D, Kaspal P, Khatiwada A, Mohapatra R \& Nash H (2014). Manis crassicaudata. The IUCN Red List of Threatened Species 2014: The IUCN Red List of Threatened Species 2014: e.T12761A45221874. https://dx.doi.org/ 10.2305/IUCN.UK.20 14-2.RLTS. T12761 A45221874.en. Downloaded on 11 February 2019.

6. IUCN (2014). IUCN Red List of Threatened Species. IUCN, Gland.

7. IUCN (1996). IUCN Red List of Threatened Species. IUCN, Gland.

8. Irshad N, Mahmood T, Hussain R \& Nadeem MS (2015). Distribution, abundance and diet of the Indian
Pangolin (Manis crassicaudata). Anim Biol 65(1): 57-71.

9. CITES (2000). Amendments to Appendices I and II of the Convention adopted by the Conference of the Parties at its 11th meeting, Gigiri (Kenya). CITES, Geneva, Switzerland.

10. Pantel S \& Chin SY (2008). Current status of Chinese pangolin Manis pentadactyla in the wild: a rapid range wide population assessment. In Proceedings of the Workshop on Trade and Pangolins Native to South and Southeast Asia. (Singapore Zoo). JuneJuly, pp 103.

11. Chakravorty J, Meyer-Rochow VB \& Ghosh S (2011). Vertebrates used for medicinal purposes by members of the Nyishi and Galo tribes in Arunachal Pradesh (North-East India). J Ethnobiol Ethnomed 7(1): 1-13.

12. Mahmood T, Jabeen K, Hussain I \& Kayani AR (2013). Plant species association, burrow characteristics and the diet of the Indian Pangolin, Manis crassicaudata, in the Potohar Plateau, Pakistan. Pak J Zool 45(6): 1533-1539.

13. Chao J (2002) In: Proceedings of the Pangolin Conservation stakeholder's workshop (Cambodia). November 4-5, 2008, pp 10.

14. Mohapatra RK \& Panda S (2014). Behavioural descriptions of Indian pangolins (Manis crassicaudata) in captivity. Int J Zool 795062: 1-7.

15. Mohapatra R, Panda S \& Nair M (2015). On the mating behaviour of captive Indian pangolin (Manis crassicaudata). TAPROBANICA 7(1): 57-59

16. Heath ME (1992). Manis pentadactyla. Mamm Species 414: 1-6.

17. Prater SH (1980). The Book of Indian Animals, 3rd Ed. JBNHS (Bombay), pp 428. 
18. Khan R \& Ali M (1985). Mammals of Bangladesh: A field guide. Nazma Reza (Bangladesh), pp 92.

19. Schlitter DA (2005). Order Pholidota. Wilson DE \& Reeder DM: in Mammal Species of the World, $3^{\text {rd }}$ Ed. Johns Hopkins University Press (Baltimore): 530-531.

20. Srinivasulu C \& Srinivasulu B (2012). South Asian Mammals, their Diversity, Distribution, and Status. Springer (New York), pp 468.

21. Emry RJ \& Skinner MF (1970). A North American Oligocene pangolin and other additions to the Pholidota. Bull Am Mus Nat Hist 142: 459-510.

22. Akrim F, Mahmood T, Hussain R \& Qasim (2017). Distribution pattern, population estimation and threats to the Indian Pangolin Manis crassicaudata (Mammalia: Pholidota: Manidae) in and around Pir Lasura National Park, Azad Jammu \& Kashmir, Pakistan. JoTT 9(3): 9920-9927.

23. Roberts T J (1997). The Mammals of Pakistan. Oxford University Press (New York). pp525.

24. Colbert E H (1935). Siwalik mammals in the American museum of natural history. American Philosophical Soc 26: 1-40.

25. Hutton AF (1949). Notes on the Indian pangolin (Manis erassieaudata). JBNHS 48: 805-806.

26. Israel ST, Sinclair B, Grewal \& Hoefer HJ (1987). Indian Wildlife. APA Productions Ltd (Hong Kong), pp 363.

27. Sopyan E (2009). Malayan Pangolin Manis javanica Trade in Sumatra, Indonesia. In Proceedings of the Workshop on Trade and Conservation of Pangolins Native to South and Southeast Asia (Patel S \& Chin SY) (Singapore Zoo, Singapore) 30 June-2 July 2008.

28. Chin SY \& Pantel S (2009). Pangolin capture and trade in Malaysia. Proceedings of the workshop on trade and conservation of pangolins native to South and Southeast Asia. 30: 138-157.

29. Nowak RM (1999). Walker's Mammals of the World. 6th Ed. Johns Hopkins University Press (Baltimore), pp 642643.

30. Wu SB \& Ma G (2007). The status and conservation of pangolins in China. Traffic East Asia Newsletter (4): 1-5.

31. Mahmood T, Hussain R, Irshad N, Akrim F \& Nadeem MS (2012). Illegal mass killing of Indian pangolin (Manis crassicaudata) in Potohar region, Pakistan. Pak J Zool 44(5): 1457-1461.

32. Mahmood $\mathrm{T}$, Irshad $\mathrm{N} \&$ Hussain $\mathrm{R}$ (2014). Habitat preference and population estimates of Indian pangolin (Manis crassicaudata) in District Chakwal of Potohar Plateau, Pakistan. Russ J Ecol 45(1): 70-75.

33. Mahmood T, Andleeb S, Anwar M, Rais M, Nadeem M S, Akrim F \& Hussain R (2015). Distribution, abundance and vegetation analysis of the Scaly Anteater (Manis crassicaudata) in Margalla Hills National Park Islamabad, Pakistan. J Anim Plant Sci 25(5): 1311-1321.

34. Harrisson T \& Loh CY (1965). To scale a pangolin. Sarawak Mus 12(25-26): 415418.

35. SATCM (State Administration of Traditional Chinese Medicine) (1996). Guangxi Province: Cross-border trade prices for pangolins rise further. Zhongyaocai (State Administration of Traditional Chinese Medicine) 19(4).

36. Kang S \& Phipps MJ (2003). A question of attitude: South Korea's traditional medicine practitioners and wildlife conservation. TRAFFIC East Asia.

37. Gubbi S \& Linkie M (2012). Wildlife hunting patterns, techniques, and profile of hunters in and around Periyar tiger reserve. J Bombay Nat Hist Soc 109(3): 165-172. 
38. Mohanty B (2011). Wildlife poaching in Orissa. PhD Thesis. Dept of Life Sci, North Orissa Univ, Baripada, Odisha, pp 82-85.

39. Mitra S (1998). On the scales of scaly anteater Manis crassicaudata. JBNHS 95(3): 495-498.

40. Indian Wildlife Club Ezine (2004). Pangolin or scaly anteater (Manis crassicaudata). Wild bites IWC's monthly newsletter March, 2004.

41. Challender DWS \& Hywood L (2012). African pangolins under increased pressure from poaching and intercontinental trade. TRAFFIC Bulletin 24(2): 53-55.

42. Lim NTL \& Ng PKL (2007). Home range, activity cycle and natal den usage of a female Sunda pangolin Manis javanica (Mammalia: Pholidota) in Singapore. Endanger Spp Res 3: 1-8.

43. Yang CW, Chen S, Chang CY, Lin MF, Block E, Lorentsen R, Chin JS \& Dierenfeld ES (2007). History and dietary husbandry of pangolins in captivity. Zool Biol 26(3): 223-230. 